\title{
EFFECT OF COPPER SULPHATE LEVEL IN THE DIET ON BROILER PERFORMANCE AND CARCASS QUALITY
}

\author{
Hassan Tarsha and Riad Al- Munajed \\ Faculty of Vet. Med., El-Bath Univ. Syria
}

\begin{abstract}
The present experiment was carried out on 480 c0mmercial broiler chicks to determine the effect of adding copper sulphate on growth performance (body weight, food conversion, mortality) and on carcass quality (cholesterol and copper level in breast muscles but only copper concentration in liver).

Four groups of birds, each of 120 chicks were used. Experimental diets were formulated from vegetable feeding stuffs, corn, and soybean meal and feed additives to cover the requirements in two phases of feeding program (First, from 1 to 21 days \& second from 22 to 42 days) at the period of the experiment. The first group was fed on basal diet without any copper sulfate supplement. The second, third and fourth groups were fed on the basal diet supplemented with 150, 250 , and $350 \mathrm{mg} \mathrm{Cu} \mathrm{SO}_{4 /} \mathrm{Kg}$ feed respectively.

The results demonstrated that supplementation of feed with copper sulphate, 250 or $350 \mathrm{mg} \mathrm{kg}$ feed had significant positive effects on growth until the fourth week as compared to control group, but the second group fed $150 \mathrm{mg} \mathrm{kg}$ copper sulphat had no significant difference during the experiment periods.

On the other hand there were no significant difference in feed conversion ratio, mortality rate and copper level in the liver and breast muscle between the control group and the groups fed on different levels copper sulphate supplemented diets but cholesterol level in breast muscles was decreased with increasing copper sulphate level in the diet to $350 \mathrm{mg} / \mathrm{kg}$.

It was concluded that the addition of copper sulphate in high concentration (up to $350 \mathrm{mg} \backslash \mathrm{kg}$ ) was safe and has a positive effect on growth and reduced cholesterol level in the breast meat.
\end{abstract}

Key Words: Copper sulphat, Broiler performance, Carcass quality. 


\title{
تأثير معدل كبريتات النحاس في الخطلة على الكفاءة الإتتاجية لفراخ اللحم ونوعية الذبيحة
}

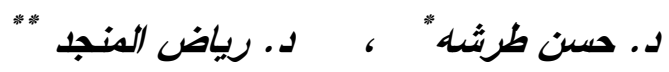 \\ " أستاذ مساعد - كلية الطب البيطرى - جامعة البعث / سوريا \\ ملخص البحث
}

أجريت التجربة لتحديد تأثير إضافة كبريتات النحاس على الكفاءة الإنتاجية (الوزن الحي، معامل التحويل الغذائي و نسبة النفوق) و نوعية الذبيحة (تركيز الكولسترول و النحاس في عضلات الصدر ) و تركيز النحاس في الكبد.

استخدم صيصان أحد الهجن التجارية للفروج و التي قسمت إلى أربع مجموعات كل منها مؤلفة من 120 طير • بدأت الطيور بتتاول الخلطات التجريبية في عمر أسبوع و استمرت التجربة حتى عمر 42 يوماً.

تم تكوين الخلطات العلقية من مواد علف نباتية قو امها الذرة الصفر اء وكسبة فول الصويا و المتممات المختلفة. وقد قسمت مرحلة التربية إلى مرحلتين : الأولى من 1- 21 يوماً و الثانية من من 22 - 42 يوماً . تتاولت المجموعة الأولى الخلطة الأساسية دون أي إضافات طيلة فترة التجربة و التي مثلت مجموعة الثاهد للمقارنة وتتاولت المجموعة الثانية الخلطة الأساسية مضافاً إليها كبريتات النحاس بكمية 150ملغ/كغ علف أما المجموعة الثالثة فقد تتاولت الخلطة الأساسية مضافاً إليها 250 ملغ/ كغ و الرابعة الخلطة الأساسية مضافاً إليها 350 ملغ كبريتات النحاس/كغ من الخلطة العلفبة. بينت النتائج أن إضافة كبريتات النحاس بجرعات 250 - 350 ملغ/كغ علف كان لها تأثير إيجابي على زيادة الوزن الحي وكان الفرق معنوي حتى الأسبوع الر ابع من العمر (p>0.05) و ( (p<0 على التو الي مقارنة بمجموعة الثاهد، لكن لم يكن هناك أي فروق معنوية طيلة فترة 01 التربية عند المجموعة الثانية و التي نتاولت 150 ملغ/كغ كبريتات نحاس.أما بالنسبة لمعامل * أستاذ مساعد - كلية الطب البيطري / جامعة البعث. 
التحويل الغذائي و نسبة النفوق فأنها لم تتأثر بإضافة كبرينات النحاس ، وكذلك لم تؤثر إضافة هذا

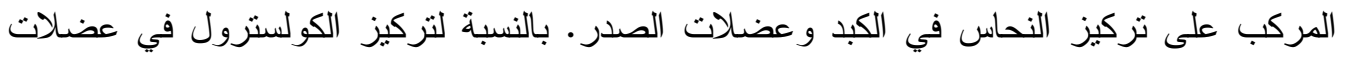
الصدر انذفض مع زيادة تركيز كبريتات النحاس إلى 350 ملغ/كغ في الخلطة العلفية (01 .01).

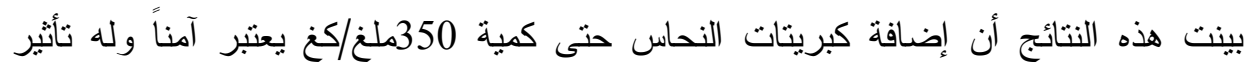
إيجابي على زيادة الوزن الحي وعلى تخفيض تركيز الكولسترول في لحم الصدر. الكلمات المفتاحية: كبريتات النحاس، الفروج، الكفاءة الإنتاجية، نو عية الذبيحة.

\section{مقدمة INTRODUCTION:}

تلعـب الإضافات العلفية المختلفة أهمية حيوية في صناعة الدواجن الحديثة وخصوصاً

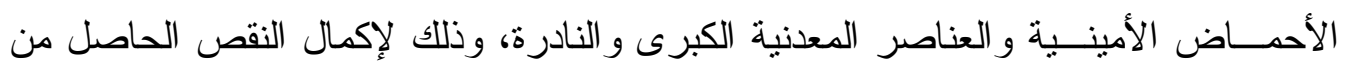

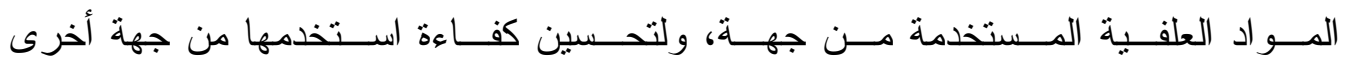

.(Aoyagi\&Baker,1993)

درســت أهمـية العناصـر المعدنـية في العديد من الأبحاث العلمية على الحيوانات

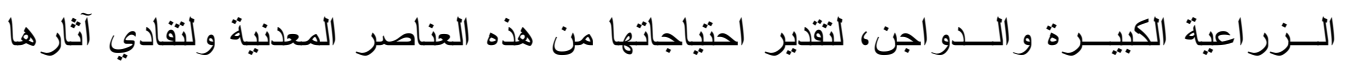
السلبية على صحة الحيوانات و إنتاجيها، ولكن القليل من الأبحاث ركزت على تأثير العناصر

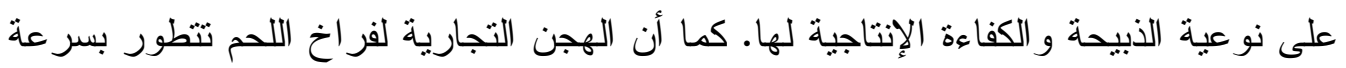

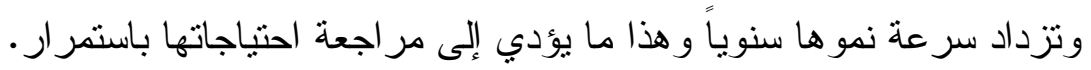

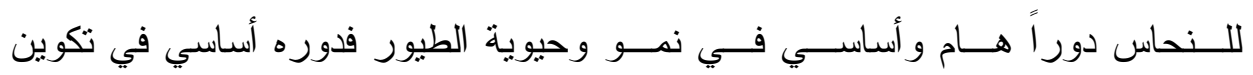
هيموغلوبين الدم فإذا غاب النحاس لا يستطيع الحديد أن يدخل في عملية تكوين الهيمو غلوبين

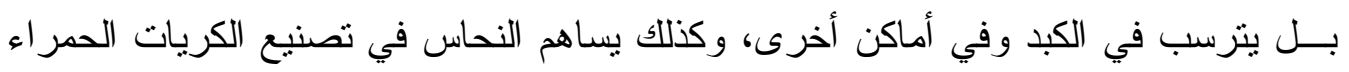

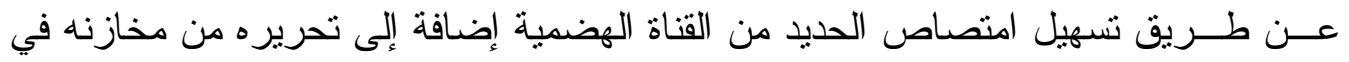

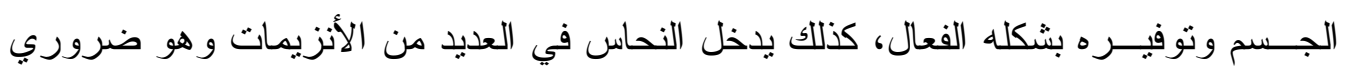
لتكوين الصباغات في الريش (Aoyagi \&Baker,1995). 
تستخدم مركبات النحاس كمضادة للأحياء الدقيقة (Genaro et. al., 1985 ) ، وكإضافة علفية محفزة للنمو فقد وجد (Banks et. al. 2004) أن للنحاس تأثنر على مدى الاستفادة مــن الفسفور عند الطيور، فمعدله ونوعية مصدره تؤثز على معدل نركيز الفسفور في جسم الطائــر ، وتؤثــر إضـافة النحاس إلى الأعلاف في أكسدة الفيتامينات (Luo et. al. 2005)، وكـذلك وجـــد أن للنحاس تأثنير على مدى الاستفادة من الفسفور عند الطيور، فمعدله ونوعية مصدره تؤثر على معدل احتباس الفسفور في جسم الطائر (Banks, et. al., 2004.).

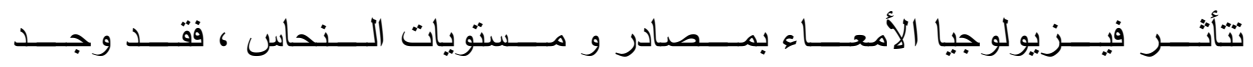
أن مركبات النحاس قللت من عدد الخلايا اللمفاوية في الأمعاء. تـستخدم مــركبات النحاس كمضادة للأحياء الدقيقة (Gennaro et. al., 1985$)$ وكإضافة علفية محفزة للنمو (Banks et. al. 2004). فقــد وجد (Arias \& Koutsos 2006) أن إضافة كبريتات النحاس بمعدل 188 ملغ /كـــ مــن الخلطة العلفية لها تأثير ها الإيجابي على زيادة الوزن الحي للطيور، بينما لم يجد (Baker et. al., 1991) على شكل كبريتات النحاس أو الأملاح الأخرى. ولكــنهـ يعــتقد أن كبــريتات الــنحاس هي الأفضل من بين مصـادر النحاس الأخرى لإضـــافتها إلــى الخلطــات العلفية. فقد أثنار (Kim et. al., 1992) أن للنحاس تأثير على الثى تزكيـز بــروتين Glutathione فــي الخلايـــا الكـبدية وبالتالي التأثير على عملية تصنيع الكولـسترول،وبين (ŠEVČÍKOVÁ et. al., 2003) أن إضـــافة الـــحاس علــى شكل كبــريتات الــنحاس إلـى علف طيور الفروج خفض محتوى الدهن الكلي و الكولسترول في الذبيحة، لكن لم يؤثر على نوعية الأحماض الدهنية. يــضـاف الـــحاس أحسـياناً إلـىى الخلطــات العلفـية بكمـيات كبيــرة كمحفز للنمو أو كمضاد للفطريات، فقد أدت إضافة مركبات النحاس بكمية 400 - 800 ملغ/كغ علف إلى انخفاض في متوسط كمية العلف المتتاولة ومعدل النمو و يزداد نزكيز النحاس في الكبد بشكل Ledoux et. al., 1987; Luo et. al. ( خطي عــند زيادة النحاس إلى الخلطات العلفية .2005 


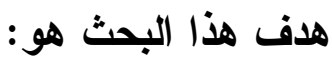

در اســة تأثيــر إضــافة كبـريتات الـــحاس علـى الكفاءة الإتناجية (الوزن الحي ،

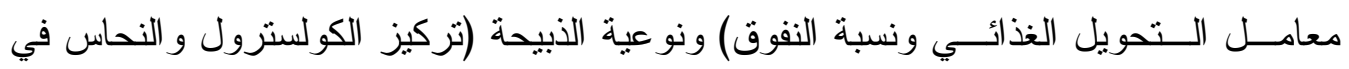
عضلات الصدر). (- مات.

\section{مواد وطرائق البحث Materials \& Methods:}

تـــم إجر اء البحث على أربع مجموعات من صيصان أحد الهجن التجارية للفروج كل مـنها 120 كــنكوت ، تمت تربيتها في حظيرة أبحاث تغذية الدو اجن. جهزت الحظيرة بكافة

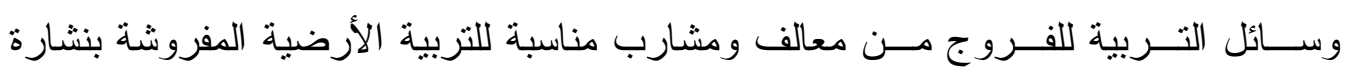

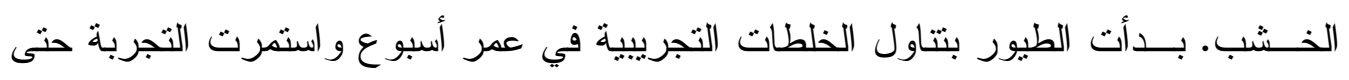
عمر 42 يوماً.

لقحـت الطيور في عمر 7 أيام بلقاح مختلط للوقاية من مرض النيوكاسل و البرونثيت

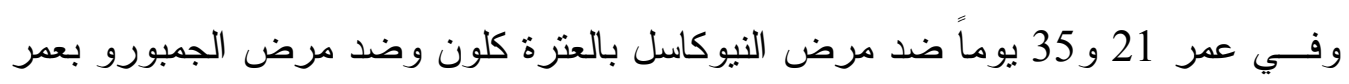
14 و 28 يوماً ، جميع اللقاحات أعطيت قطرة بالعين. تــم تكــوين الخلطـات العلفية من مو اد علف نباتية قو امها الذرة الصفر اء وكسبة فول

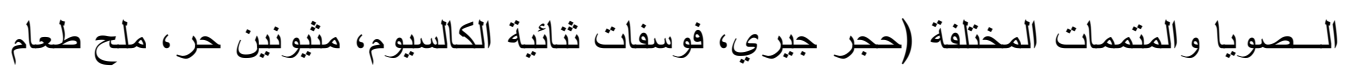

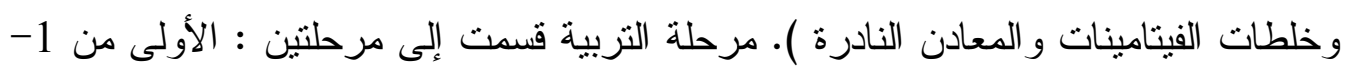
21 يوماً و الثانية من 22 - 42 يوما. يختلف تركيب الخلطات العلفية وفقاً لهاتين المرحلتين. تتاولت المجموعة الأولى الخلطة الأساسية وفق المرحلة المحددة دون أي إضافات طيلة فترة

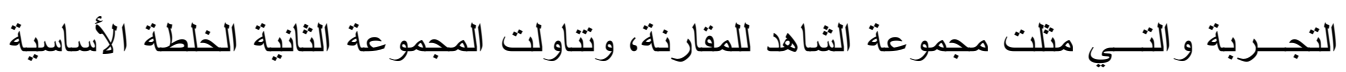
مضافاً إليها كبرينات النحاس بكمية 150ملغ/كغ علف أما المجموعة الثالثة فقد تناولت الخلطة

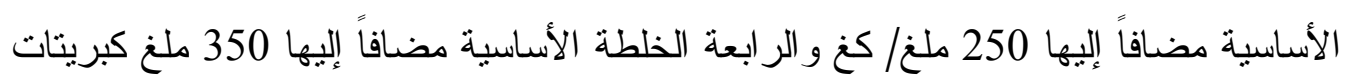
النحاس/كغ من الخلطة العلفية. 


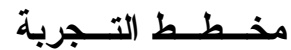

\begin{tabular}{|c|c|c|c|c|}
\hline $\begin{array}{c}\text { المجموعة الر ابعة } \\
\mathrm{CuSO}_{4}+\end{array}$ & المجموعة الثالثة & $\begin{array}{c}\text { المجموعة الثانية } \\
\mathrm{Cuso}_{4}+\end{array}$ & المجموعة الأولى & المجموعات \\
\hline الخلطة الأساسية & الخلطة الأساسية & الخلطة الأساسية & الخلطة الأساسية & \multirow{2}{*}{ الخلطات العلفية المقدمة } \\
\hline 350ملغ/كغ & 250ملغ/كغ & 150ملغ/كغ & (بدون إضافة) & \\
\hline
\end{tabular}

اســتخدم الحاســب الآلي في تكوين الخلطات العلفية وحساب قيمتها الغذائية وموازنتها بحـيث تكون جمبعها منتـابهة في هذه القيم ولكافة المجمو عات ضمن مرحلة التربية الو احدة. الجدول رقم ( 1) يبين نركيب الخلطات العلفية لمرحلتي التربية الأولى و الثانية و الجدول رقم (2) يبين القيم الغذائية لهذه الخلطات. تم جرش وخلط المو اد العلفية في وحدة التجارب وقدم العلــف للطــيور بـشكل جريش مخلوط دون تقنين ووفقا لثهية الطائر (ad-libitum).تم أســبو عيا فـي نفـس الــيوم و الساعة وزن الطيور الحية بشكل فردي وحسبت كمية العلف المستهلكة من قبل كل مجمو عة. كما تم حساب معامل التحويل الغذائي وفقا للمعادلة التالية :

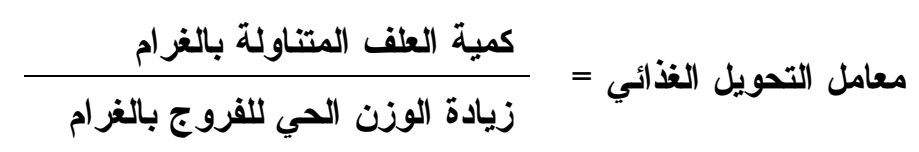

تــم فـي نهاية الأسبوع السادس ذبح ست طيور من كل مجموعة ثنلاث إناث وثناث ذكــور ومن ثم أخذت عينات من لحم الصدر ومن الكبد لقياس تزكيز النحاس في الكبد ولحم (AOAC. 2000- Official Methods of Analysis) الـصدر باستخدام التزميد الرطب وبعدها القياس بجهاز الامتصاص الذري نوع شيمادزو (AA-6800/Flame)، وقياس نزكيز الكولسترول في عضلات الصدر (Allain et. al., 1974) . أجــريت الدراسة الإحصائية باختبار T لمعرفة إذا كانت هناك فروقات معنوية بين

النتائج في المجمو عات المختلفة وفقاً ل (Yamen 1973). 


\section{النتائج Results}

بــبن الجـدول رقــ( 3 ) تأثير إضافة كبريتات النحاس على متوسط الوزن الحي

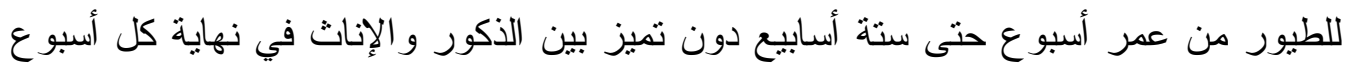

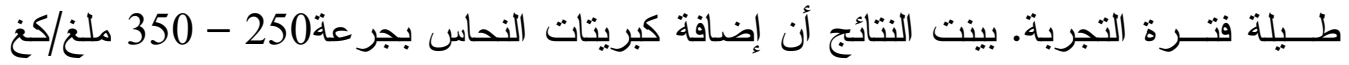

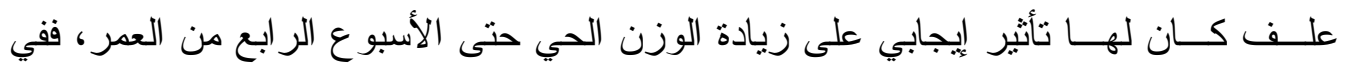

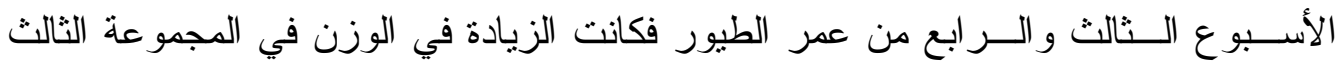

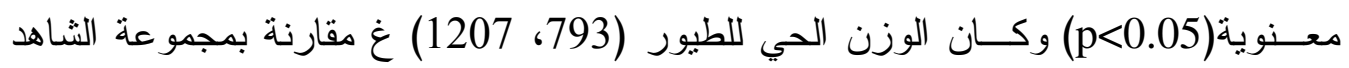

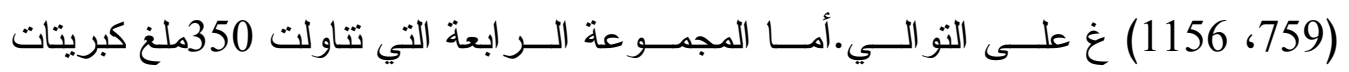

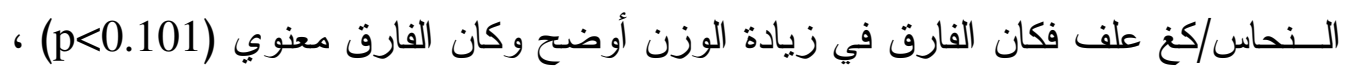

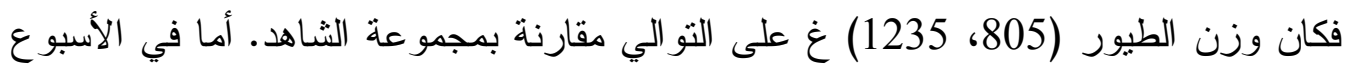

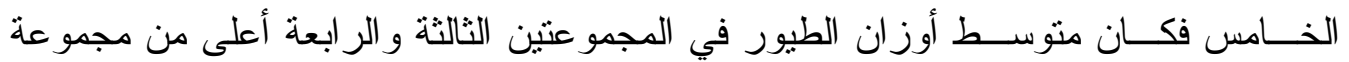

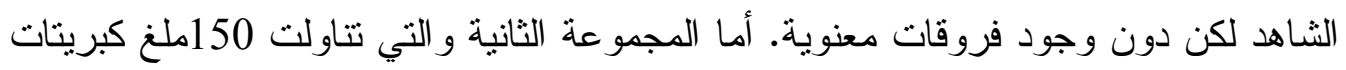

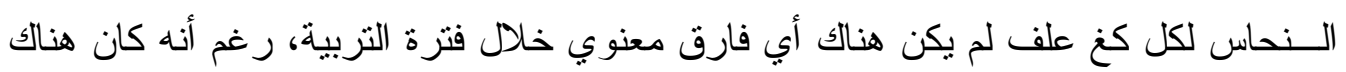
زيادة في الوزن الحي مقارنة بمجموعة الثاهد ولكن غير معنوية.

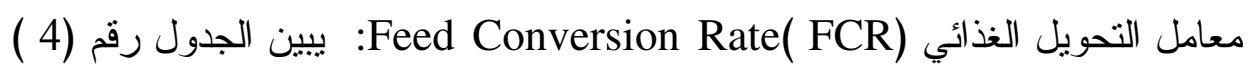

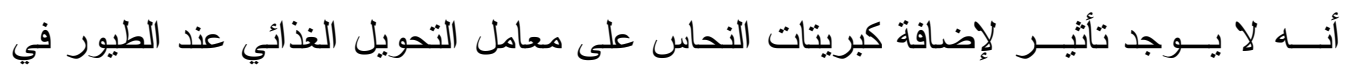

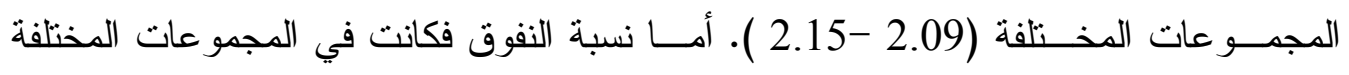
ضمن المعدل المقبول ومتقاربة ( 2.3 - 3.8 ) و هذا يدل على أن نسبة النفوق لم تتأثر بنسب النب إضافة كبريتات النحاس في المجموعات المختلفة.

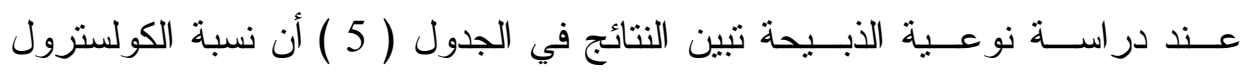
انخف ضضت بـشكل خطي متتاسبة مع ازدياد نسبة إضافة كبريتات النحاس إلى الخلطة العلفية

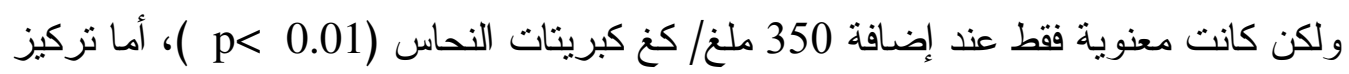

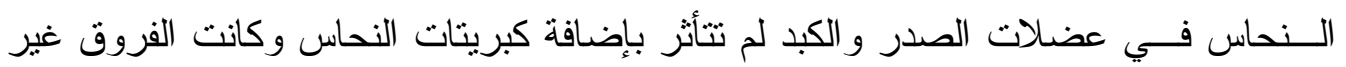

$$
\text { معنوية كما في الجدولين (6 و و7). }
$$

$\overline{\text { Kafrelsheikh Vet. Med. J. Vol. } 7 \text { No. } 1 \text { (2009) }}$ 


\section{: Discussion المناقشة}

بيــنت هـــهـ النـائج أن إضــافة كبرينات النحاس إلى الخلطات العلفية للفروج كان

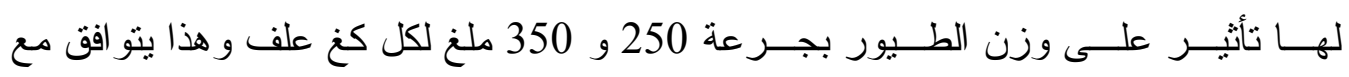
(Genaro et. al., 1985)

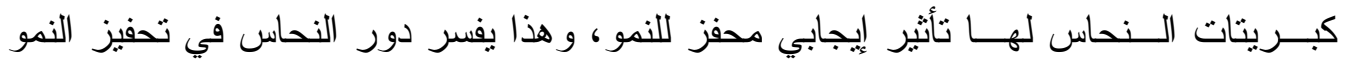

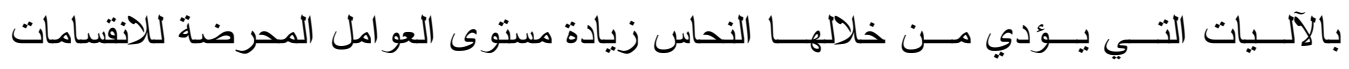

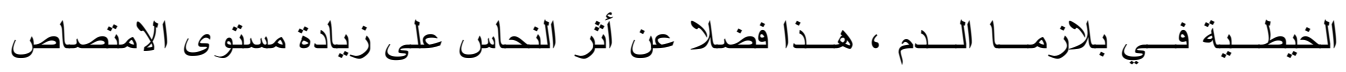

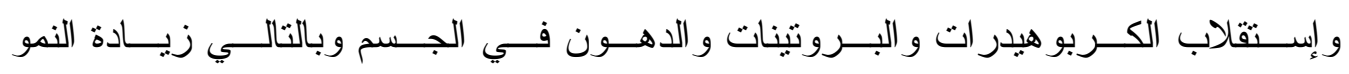
(Pesti \&Bakalli, 1996) و وأكسدة الحمض الأميني اللايسين وتوفير الحديد بشكله الفعال. أما (Banks et. al., 2004) لم يجد أي تأثير لكبريتات النحاس على الوزن الحي. بينما كان

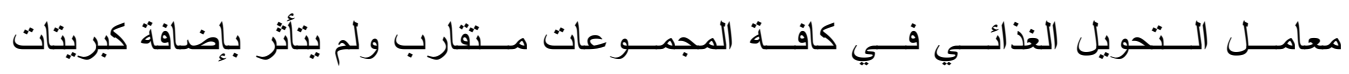
النحاس بثكل و اضح، فقد بين (Miles et. al., 1998) أن إضافة كبريتات النحاس بجرعات

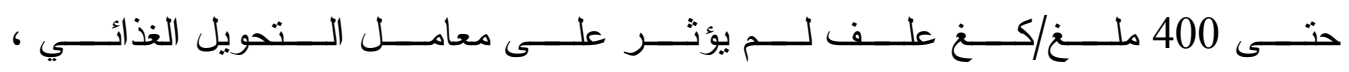

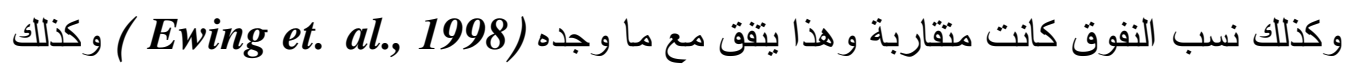
(ŠEVČÍKOVÁ1 et. al., 2003) بين( 0 و400) ملغ/كغ لم تؤثر بثكل معنوي على نسبة النفوق. إن انخفــاض مـسنوى الكولــسترول فــي عضلات الصدر الذي ظهر من نتائج هذه

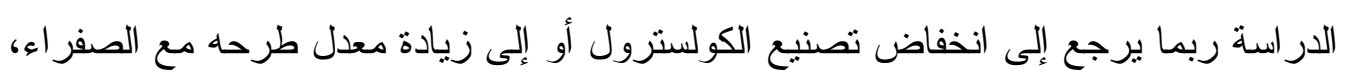

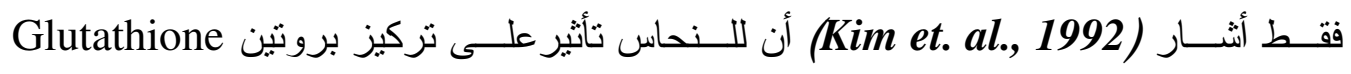

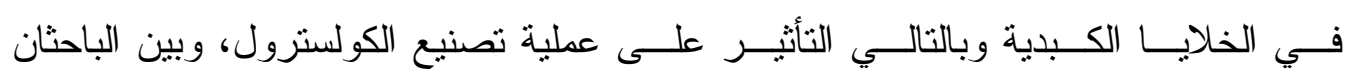
إسىى أن دور بروتين Galasala \& Kurup, 1987) HMG-CoA reductase 
Effect Of Copper Sulphate Level In The Diet...

مسنوى النحاس في عضلات الصدر و الكبد لم تتأثر بالجرعات الإضافية من كبريتات الــنحاس على عكس ما أنشارا إليه (Ledoux et. al., 1987) و (Luo et. al. 2005) من

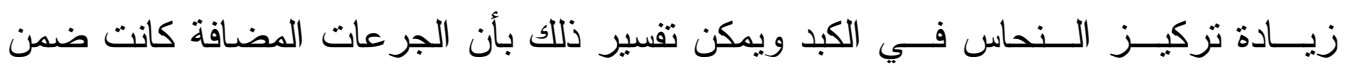
الجر عات الفسيولوجية أو قريبة منها كما أثنارا إليها العالمان (Aoyagi \& Baker,1992). يستخلص من هذه النتائج أن إضافة كبرينات النحاس بجرعة 250-350ملغ/كغ آمناً وله تأثثر إيجابي على زيادة الوزن الحي وعلى تخفيض تركيز الكولسترول في لحم الصدر. جدول رقم (1): الخلطات العلفية الأساسية المستخدمة في النجربة.

\begin{tabular}{|c|c|c|}
\hline المرحلة الثائية 22- 42يوماً & المرحلة الأولى 1- 21 يوماً & 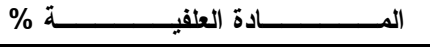 \\
\hline 60.94 & 60.94 & 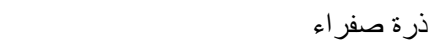 \\
\hline 35 & 35 & كسبة صويا 44\% \\
\hline 2.1 & 2.1 & فوسفات ثنائية الكالسيوم \\
\hline 1 & 1 & كربونات الكالسيوم \\
\hline 0.05 & 0.05 & ل لايسين حر \\
\hline 0.21 & 0.21 & مثيونين حر \\
\hline 0.4 & 0.4 & ملح طعام \\
\hline 0.1 & 0.1 & كلوريد الكولين \\
\hline 0.1 & 0.1 & خلطة فيتامينات * \\
\hline 0.1 & 0.1 & خلطة معادن نادرة "** \\
\hline 100 & 100 & 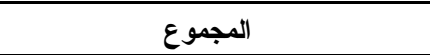 \\
\hline
\end{tabular}

" كل 1 كغ من العلف الجاهز يحتوي على المعادن التالية: 120 ملغ منغنيز 100 100 ملغ زنك ملغ منغز 40 20 1 0.3
" كل 1 كغ من العلف الجاهز يحتوي على الفيتامينات التالية:

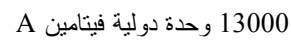

D3 5000

E ملغ فيتامين 80

K3 4

B1 ملغ فيتامين 6

B2 8

B6 ملغ فيتامين فيتامين 4

0.2 ملغ فيتامين ملغ فينامين 0.12

0.12 ملغ بيوتين

2

85

22 
Hassan Tarsha \& Riad Al-Munajed

جدول رقم (2): القيم الغذائية لخلطات مرحلتي التربية.

\begin{tabular}{|c|c|c|}
\hline المرحلة الثانية 22- 42 يوماً & المرحلة الأولى 1 - 21 يوماً & المكونات الغذائية \\
\hline 2841 & 2841 & طاقة قابلة للتمثيل كيلو كالوري /كغ \\
\hline 20.40 & 20.40 & 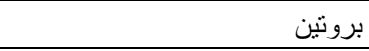 \\
\hline 139.27 & 139.27 & * $\mathrm{C} / \mathrm{P}$ \\
\hline 1.14 & 1.14 & لايسين \% \\
\hline 0.52 & 0.52 & مثيونين \% \\
\hline 0.86 & 0.86 & مثيونين + سيستين \% \\
\hline 0.24 & 0.24 & تربتوفان \\
\hline 1.02 & 1.02 & كالسيوم \% \\
\hline 0.63 & 0.63 & فوسفور كلي \% \\
\hline 0.42 & 0.42 & فوسفور ممتص \% \\
\hline 0.17 & 0.17 & صوديوم \% \\
\hline 0.28 & 0.28 & كلور \% \\
\hline 1.5 & 1.5 & حامض لينولييك \% \\
\hline 4.14 & 4.14 & ألياف خام \\
\hline
\end{tabular}

هي نسبة الطاقة إلى البروتين

جـدول رقـم (3): متوسط الوزن الحي الأسبوعي للطيور ( غ ) ـ الخطأ القياسي في المجموعات المختلفة للتجربة.

\begin{tabular}{|c|c|c|c|c|}
\hline المجموعة الرابعة & المجموعة الثالثة & المجموعة الثانية & المجموعة الأولى & الأسبوع عة \\
\hline $1.7 \pm 153$ & $3.2 \pm 151$ & $1.8 \pm 155$ & $2.3 \pm 153$ & الأول \\
\hline $\begin{array}{c}\mathrm{b} \\
4.2 \pm 418\end{array}$ & $\begin{array}{c}\mathrm{a} \\
5.3 \pm 425\end{array}$ & $\begin{array}{c}\mathrm{ac} \\
3.6 \pm 412\end{array}$ & $\begin{array}{c}\text { Abd } \\
4 \pm 405\end{array}$ & الثاني \\
\hline $\begin{array}{c}a \\
9.7 \pm 805\end{array}$ & $\begin{array}{c}\mathrm{b} \\
9.8 \pm 793\end{array}$ & $\begin{array}{c}\text { Ns } \\
8.3 \pm 783\end{array}$ & $\begin{array}{c}\text { Abc } \\
9.4 \pm 760\end{array}$ & الثالث \\
\hline $\begin{array}{c}a \\
17.1 \pm 1235\end{array}$ & $\begin{array}{c}b \\
15.3 \pm 1208\end{array}$ & $\begin{array}{c}\text { ac } \\
14.5 \pm 1169\end{array}$ & $\begin{array}{c}\text { Abd } \\
15.8 \pm 1156\end{array}$ & الر ابع \\
\hline $\begin{array}{c}\text { Ns } \\
28.8 \pm 1610\end{array}$ & $\begin{array}{c}\text { Ns } \\
25.5 \pm 1607\end{array}$ & $\begin{array}{c}\text { Ns } \\
25 \pm 1644\end{array}$ & $\begin{array}{c}\text { Ns } \\
21.7 \pm 1644\end{array}$ & الخامس \\
\hline $\begin{array}{c}\text { Ns } \\
28.9 \pm 1875\end{array}$ & $\begin{array}{c}\text { Ns } \\
26.5 \pm 1883\end{array}$ & $\begin{array}{c}\text { Ns } \\
25.2 \pm 1879\end{array}$ & $\begin{array}{c}\text { Ns } \\
23.9 \pm 1823\end{array}$ & س س \\
\hline
\end{tabular}

Ns.

الاختلاف بالأحرف اللاتينية الصغيرة هناك فرف معنوي عند

الاختلاف بالأحرف اللاتينية الكبيرة هنالك فرق معنوي عند

Kafrelsheikh Vet. Med. J. Vol. 7 No. 1 (2009) 
Effect Of Copper Sulphate Level In The Diet...

جدول رقم (4): معامل التحويل الغذائي التز اكمي ونسبة النفوق خلال فترة التربية.

\begin{tabular}{|c|c|c|c|c|}
\hline 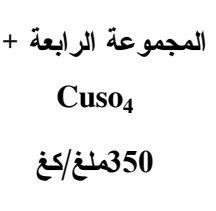 & 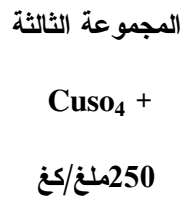 & 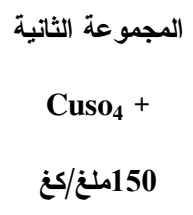 & المجموعة الأولى & الأسبوع \\
\hline 1.54 & 1.52 & 1.56 & 1.55 & الثاني \\
\hline 1.62 & 1.64 & 1.63 & 1.64 & الثالث \\
\hline 1.73 & 1.74 & 1.72 & 1.73 & الر ابع \\
\hline 1.91 & 1.92 & 1.93 & 1.93 & الخامس \\
\hline 2.09 & 2.10 & 2.13 & 2.12 & الساد \\
\hline 2.3 & 3.8 & 3 & 2.3 & نسبة النفوق \% \\
\hline
\end{tabular}

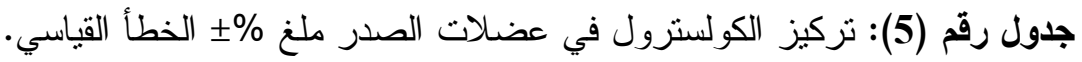

\begin{tabular}{|c|c|}
\hline & 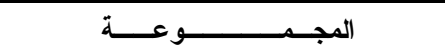 \\
\hline $\begin{array}{c}\mathrm{a} \\
0.12 \pm 0.160\end{array}$ & المجموعة الأولى - الثاهد \\
\hline $\begin{array}{c}\mathrm{ab} \\
\mathbf{0 . 0 6} \pm \mathbf{0 . 1 5 0}\end{array}$ & المجموعة الثانية + Cuso ، 150 ملغ/كغ \\
\hline $\begin{array}{c}\mathrm{b} \\
0.09 \pm 0.130\end{array}$ & المجموعة الثالثة + CusO ، 250ملغ/كغ \\
\hline $\begin{array}{c}c \\
0.03 \pm 0.075\end{array}$ & المجموعة الر ابعة + Cuso ، 350 ملغ/كغ \\
\hline
\end{tabular}

جدول رقم ( 6): تركيز النحاس في عضلات الصدر (ملغ/كغ) ذالخطأ القياسي.

\begin{tabular}{|c|c|}
\hline & المجـــــــــــــــــــــة \\
\hline $0.017 \pm 0.055$ & المجموعة الأولى - الثـاهد \\
\hline $0.018 \pm 0.058$ & المجموعة الثانية + \\
\hline $0.021 \pm 0.057$ & المجمو عة الثالثة + CusO $،$ ، 250ملغ/كغ \\
\hline $0.022 \pm 0.060$ & 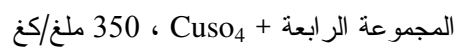 \\
\hline
\end{tabular}

$\overline{\text { Kafrelsheikh Vet. Med. J. Vol. } 7 \text { No. } 1 \text { (2009) }}$ 
جدول رقم (7): نركيز النحاس في الكبد (ملغ/كغ) دالخطأ القياسي.

\begin{tabular}{|c|c|}
\hline & المجـــــــــــوعــــة \\
\hline $\begin{array}{c}\text { Ns. } \\
0.17 \pm 2.33\end{array}$ & المجموعة الأولى - الثاهد \\
\hline $\begin{array}{c}\mathrm{Ns} \\
0.48 \pm 2.89\end{array}$ & المجموعة الثانية + Cuso $،$ ، 150ملغ/كغ \\
\hline $\begin{array}{c}\mathrm{Ns} \\
0.88 \pm 2.18\end{array}$ & 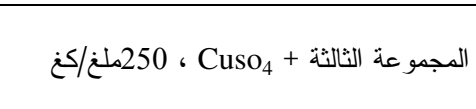 \\
\hline $\begin{array}{c}\mathrm{Ns} \\
0.57 \pm 2.35\end{array}$ & الدجموعة الر ابعة + Cuso $،$ ، 350 ملغ/كغ \\
\hline
\end{tabular}

\section{REFERENCES}

- AOAC. (2000): Official Methods of Analysis. Veterinary Analytical Toxicology.

- Allain, C.C. Poon, L.S., Chan, C.S. Richmond, W. \& Paul, C.F. (1974): Enzymatic determination of total cholesterol. Clin. Chem., 20: 470-475.

- Aoyagi, S. \& Bakere,D.H. (1992): Bioavailability of copper inorganic and organic copper supplements for young chicks. Poult.Sci., 71: 68.

- Aoyagi, S. \& Bakere, DH. (1993): Nutritional evaluation of copperlysine and zinc- lysine complexes for chicks. Poult. Sci., 72; 165-171.

- Aoyagi, S. \& Baker, D.H. (1995): Effect of high copper dosing on hemicelluloses digestibility in cecectomized cockerels. Poult. Sci., 74; 208-211.

- Arias, V.J.\& Koutsos, E.A. (2006): Effects of copper source and level on intestinal physiology and growth of broiler chickens. Poult Sci., 85 (6):999-1007. 
- Baker, D.H., Odle, J. Funk, A.M. \& Konjufca, V. (1991): Research note: Bioavailability of copper in cupric oxide, cuprous oxide, and in a copper-lysine complex. Poult. Sci., 70 ; 177-179.

- Banks, K.M., Thompson, K.L., Jaynes, P.\& Applegate, T.J. (2004): Effects of copper source on phosphorus retention in broiler chicks and laying hens. Poult Sci., 83 (6): 990-996.

- Ewing, H.P., Pesti, G.M., Bakalli, R.I. \& Menten, J.F. (1998): Studies on the feeding of cupric sulfate pentahydrate, cupric citrate, and copper oxychloride to broiler chickens. Poult Sci.;77(3):445-448.

- Gennaro, A.R., Chase, G.D., Gibson, M.., Granberg, C.B., Harvey, S.C., King, R.E., Martin, A.N., Med wick, T. Swinyard, E.A., \&Zink, G.L. (1985): Remington's Pharmaceutical Sciences. 17th ed., MARK, Philadelphia College of Pharmacy and Science.

- Kim, S., Chao, P.Y., \& Allen, G.D.A. (1992): Inhibition of elevated hepatic glutathione abolishes copper deficiency cholesterolemia. FASAB J., 6: 1060-1068.

- Ledoux, D.R., Miles, R.D., Ammerman, C.B., Harms, R.H., (1987): Interaction of dietary nutrient concentration and supplemental copper on chick performance and tissue copper concentrations. Poult. Sci., 66: 1379-1384.

- Luo, X.G., Ji, F., Lin, Y.X., Steward, L., Lu, L., Liu, B., \& Yu, S.X. (2005): Effects of dietary supplementation with copper sulfate or tribasic chloride performance, relative copper Bioavailability, and oxidation stability of vitamin E in feed. Poult. Sci., 84: 888-893. 
- Miles, R.D., Keefe, S.F., Henry, P.R., Ammerman, C.B. \& Luo, X.G. (1998): The effect of dietary supplementation with copper sulfate or tribasic copper chloride on broiler performance, relative copper bioavailability, and dietary prooxidant activity. Poult Sci.;77: 416425.

- NRC, (1994): Nutritional Requirements of Domestic Animals Nutrient Requirements of poultry, Natl. Acad. Sci., Washington D.C. 120p.

- Pesti, G.M., \& Bakalli, R.L. (1996): Studieon The feeding of cupric sulfate pentahydrate and cupric citrate to broiler chickens. Poult. Sci., 75: 1086- 1091.

- Valsala, P; \& Kurup,P.A. (1987): Investigation on the mechanism of hypercholesterolemia observed in copper deficiency in rats. J. Bio. Sci., 12: 137-142.

- Yamen, T. (1973): Statistics an introductory analysis. Harper international Edition,. Now York 780p.

- Skřivan M., Ševčíková S., Tůmová E., Skřivanová V., Marounek M. (2002): Effect of copper supplementation on performance of broiler chickens, cholesterol content and fatty acid profile of meat. $\underline{\text { Czech J. }}$ Anim.Sci., 47: 275-280.

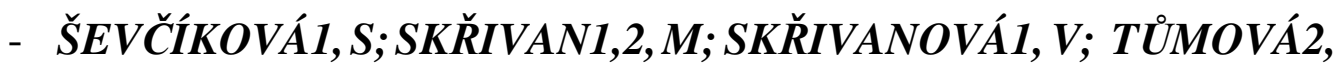
$\boldsymbol{E} \&$ \&OUCKÝ1, M. (2003): Effect of supplementation of copper in copper sulphate and $\mathrm{Cu}$-glycine on fatty acid profile in meat of broiler chickens, cholesterol content and oxidation stability of fat. Czech J. Anim. Sci., 48 (10): 432-440. 